\title{
A Influência da declividade do terreno e do tempo de experiência dos operadores no rendimento do feller buncher
}

\author{
Terrain slope and operators experience time \\ influence on feller buncher yield
}

\author{
Ricardo Hideaki Miyajima ${ }^{1}$, Rodrigo Petrongari Tonin'1, \\ José Raimundo de Souza Passos² e Paulo Torres Fenner ${ }^{3}$
}

\begin{abstract}
Resumo
A declividade do terreno e o tempo de experiência dos operadores afetam significativamente o rendimento e, por consequência, os custos da colheita de madeira, que é uma das atividades mais onerosas da cadeia produtiva de florestas plantadas. Foi estudado um sistema de colheita de arvores inteiras (full tree) comparando o rendimento do feller buncher em função da declividade do terreno e do tempo de experiência dos operadores. A floresta clonal de eucalipto, foi plantada com um espaçamento de plantio de 3,00 m x 2,00 $\mathrm{m}$ e no momento da colheita estava com 6 anos de idade. Os dados foram obtidos por meio de um estudo de tempos e rendimentos, pelo método do tempo contínuo. Foram determinados o rendimento, a eficiência operacional e o tempo efetivo médio do ciclo. O rendimento médio da colheita com o feller buncher diminuiu com o aumento da declividade do terreno. Em média o rendimento na declividade ondulada foi de $124,92 \mathrm{~m}^{3} \mathrm{~h}^{-1}$, e na declividade plana foi de $142,00 \mathrm{~m}^{3} \mathrm{~h}^{-1}$. O ganho de rendimento, quando comparada à declividade plana em relação a declividade ondulada, foi de $16,60 \%$ para o operador 2 e de $19,93 \%$ para o operador 3. Independentemente do tempo de experiência dos operadores, o rendimento foi maior no terreno plano em relação ao ondulado. Independentemente da declividade do terreno o rendimento aumentou com o aumento do tempo de experiência dos operadores. A eficiência operacional foi maior na declividade plana em relação a ondulada. A atividade parcial cortar foi a que mais consumiu tempo, seguido do giro vazio e da basculada.
\end{abstract}

Palavras-chave: colheita florestal, eucalipto, rendimento, planejamento, tempos e rendimentos.

\begin{abstract}
Terrain slope and operators time of experience significantly affect yield and, consequently, wood harvesting costs, which is one of the most costly activities of productive chain of planted forests. A full tree harvesting system was studied by comparing the performance of feller buncher according to the direction of slope and operators time of experience. A clonal eucalyptus forest was studied with a planting spacing of $3.00 \mathrm{~m} \mathrm{x}$ $2.00 \mathrm{~m}$ and the forest was six years old at harvesting time. Data were obtained through a study of times and yields, by the continuous time method. Determined were yield, operational efficiency and the effective average cycle time. The average yield of feller buncher decreased with the increase of the terrain slope. On average, the yield was $124.92 \mathrm{~m}^{3} \mathrm{~h}^{-1}$ for the wavy slope and was $142.00 \mathrm{~m}^{3} \mathrm{~h}^{-1}$ for the flat slope. Yield was greater when comparing flat slope to wavy slope; it was $16.60 \%$ for the operator 2 and $19.93 \%$ for the operator 3. Regardless of the operators time of experience the yield was higher on the flat terrain when compared to wavy terrain. Regardless of terrain slope yield increased with increasing operator's time of experience. In flat slope the operational efficiency was higher when compared to the wavy one. Partial activity cutting was the most time consuming, followed by empty turning and tilting.
\end{abstract}

Keywords: Harvesting, eucalyptus, yield, planning, time and yields.

\footnotetext{
${ }^{1}$ Doutorado em andamento em Ciência Florestal. UNESP - Universidade Estadual Paulista Júlio de Mesquita Filho/ FCA - Faculdade de Ciências Agronômicas. Rua José Barbosa de Barros, 1780- 18610-307 - Botucatu, SP, Brasil. E-mail: richidetoshimiyajima@hotmail.com; rptonin@fca.unesp.br.

2Professor Assistente Doutor do Departamento de Bioestatística. UNESP - Universidade Estadual Paulista Júlio de Mesquita Filho/ FCA - Faculdade de Ciências Agronômicas. Rua José Barbosa de Barros, 1780- 18610-307 - Botucatu, SP, Brasil. E-mail: jrpassos@ibb.unesp.br.

3Professor Adjunto Departamento de Ciências Florestais. UNESP - Universidade Estadual Paulista Júlio de Mesquita Filho/ FCA - Faculdade de Ciências Agronômicas. Rua José Barbosa de Barros, 1780- 18610-307 - Botucatu, SP, Brasil. E-mail: fenner@fca.unesp.br.
}

Sci. For., Piracicaba, v. 44, n. 110, p. 443-451, jun. 2016 DOI: dx.doi.org/10.18671/scifor.v44n110.17 
Miyajima et al. - A Influência da declividade do terreno e do tempo

de experiência dos operadores no rendimento do feller buncher

\section{INTRODUÇÃO}

A incorporação de novas tecnologias na colheita mecanizada de madeira de eucalipto (BRAMUCCI; SEIXAS, 2002; FIEDLER et al., 2008; SIMÕES et al, 2010a; SIMÕES et al., 2014) induz a modernização das máquinas e dos sistemas de colheita no Brasil.

Os sistemas de colheita e processamento de madeira variam em função da espécie, idade, características silviculturais, condições do terreno, finalidade do produto entre outros (SILVA et al., 2003).

A substituição do harvester pelo feller buncher, além de ser tecnicamente viável, apresentou rendimentos e custos vantajosos (SIMÕES, 2008; BERTIN, 2010). Entretanto, Nascimento et al. (2011) alegam que, tanto tecnicamente quanto economicamente existem poucos dados confiáveis para a escolha da máquina e do sistema mais adequado para cada caso.

Considerando que a colheita é uma das atividades mais onerosas da cadeia produtiva de florestas plantadas (SIMÕES et al., 2010b), fica evidente a necessidade do aperfeiçoamento constante das técnicas que visam melhorar os sistemas de colheita (MINETTE et al., 2004).

Independentemente do grau de mecanização de um sistema de colheita de madeira, é necessário avaliar tecnicamente as máquinas. Só assim é possível corrigir ou alterar adequadamente o processo de produção, visando a racionalização e a otimização dos recursos empregados (LOPES et al., 2008).

O estudo de tempos e movimentos é uma ferramenta que pode ser utilizada para buscar essas melhorias e que pode ser empregada no planejamento, controle e racionalização das operações podendo resultar em aumento de rentabilidade o qual manifesta-se através do aumento da produtividade ou pela redução dos custos de produção (VALVERDE et al., 1996; SEIXAS et al., 2004; FERNANDES et al., 2009; SIMÕES et al., 2014). De uma forma geral o estudo de tempos e movimentos auxilia compreender os fatores que exercem influência sobre a atividade que está sendo desenvolvida.

O trator florestal feller buncher é dimensionado para realizar a derrubada, que é composta pelas atividades parciais: corte, acúmulo e formação dos feixes de madeira (MALINOVSKI; MALINOVSKI, 1998; MOREIRA et al., 2004).

A derrubada é uma das etapas que compõem a colheita de madeira e é condicionada por diversos fatores, tais como: declividade, solo, operador, tipo de floresta, volume por árvore, espaçamento, tratos silviculturais, sistema de colheita, turno de trabalho, finalidade da madeira, capital disponível entre outros (VALVERDE et al., 1996; BRAMUCCI; SEIXAS, 2002; MALINOVSKI et al., 2006; FERNANDES et al., 2009; OLIVEIRA et al., 2009). No entanto, Lopes et al. (2008) afirmam que, embora pouco avaliada cientificamente, a experiência e a habilidade dos operadores são fatores chave que também influenciam na produtividade.

Desta forma o feller buncher foi estudado trabalhando na colheita de eucalipto em áreas com duas declividades (ondulada e plana). Além disso, também foi avaliado o tempo de experiência dos operadores.

\section{MATERIAL E MÉTODOS}

\section{Área de estudo}

O estudo foi conduzido em uma floresta de Eucalyptus platyphylla, localizada nas coordenadas geográficas $23^{\circ} 06^{\prime} 53.00^{\prime \prime}$ de Latitude Sul e $48^{\circ} 36^{\prime} 55.41^{\prime \prime}$ de Longitude Oeste, no Estado de São Paulo, Brasil.

Segundo a classificação de Köppen-Geiger, as características climáticas da região são consideradas como Cwa clima tropical de altitude com pluviosidade média anual de $1.372,7 \mathrm{~mm}$, e temperatura média anual de $19,7^{\circ} \mathrm{C}$.

De acordo com o Sistema Brasileiro de Classificação de Solos (EMBRAPA), o solo foi classificado como LVA, Latossolo Vermelho Amarelo, Distrófico Psamítico, A moderado, Álico, textura média.

Foram estudados dois talhões com diferentes características topográficas. O relevo do talhão 27 é plano com a declividade variando de 0 a 3\%. Já no talhão 29 o terreno é ondulado e a declividade varia de 8 a $20 \%$.

Embora os dois talhões estudados possuíssem o mesmo espaçamento de plantio, 3,00 $\mathrm{m} \times 2,00$ $\mathrm{m}$, totalizando uma densidade de 1.667 árvores por hectare, no momento da colheita, aos 6 anos de idade, o número de árvores por hectare e o volume por árvore eram diferentes. A densidade 
do talhão 27 era de 1.625 árvores por hectare, com um volume médio por árvore de $0,25 \mathrm{~m}^{3}$. Já a densidade do talhão 29 era de 1.650 árvores por hectare e o volume médio por árvore de 0,22 m³.

\section{Fatores do estudo}

Os principais fatores que podem afetar o rendimento do feller buncher são: declividade, operador, tempo de experiência, floresta, espécie, espaçamento, tratos silviculturais, volume por árvore, solo, sistema de colheita, turno de trabalho, finalidade da madeira, capital disponível entre outros. A maioria destes fatores foram mantidos constantes neste estudo, variando-se somente a declividade do terreno e o tempo de experiência dos operadores.

Foram estudadas duas classes de declividade: ondulada e plana e três operadores com diferentes tempos de experiência (Tabela 1).

Deve-se ressaltar que não foi considerado o tempo de experiência anterior dos operadores, com outras máquinas similares de colheita da madeira.

Tabela 1. Tempo de experiência dos operadores do feller buncher.

Table 1. Time of experience of feller buncher operators.

\begin{tabular}{cc}
\hline Operador & Tempo de experiência (meses) \\
\hline 1 & 3 \\
2 & 4 \\
3 & 21 \\
\hline
\end{tabular}

O equipamento estudado era composto por uma máquina base da marca John Deere, modelo $903 \mathrm{~K}$, com potência nominal de 224 kw, sistema rodante de esteiras, massa de 30.490 kg e equipado com um cabeçote feller buncher modelo FR 22.

A grua possuía um raio de alcance máximo de $6,71 \mathrm{~m}$.

O cabeçote possuía uma área para o acúmulo e formação dos feixes de madeira de 0,48 $\mathrm{m}^{2}$ e um disco de corte com raio de 558,8 $\mathrm{mm}$ (22 polegadas).

\section{Sistema de colheita}

Foi estudado o sistema de colheita de árvores inteiras (full tree). A derrubada era executada por um feller buncher, a extração da madeira por um skidder e o traçamento por uma garra traçadora.

\section{Descrição da operação de corte e formação dos feixes de madeira}

A operação de corte, acúmulo e formação dos feixes foi realizada pelo feller buncher deslocando-se no sentido do alinhamento de plantio.

O ramal, ou eito de trabalho, do feller buncher possuía uma largura total de 9 metros e era composto por 3 linhas de árvores.

Os feixes eram depositados formando ângulo de $90^{\circ}$ em relação a direção do deslocamento da máquina.

\section{Coleta de dados}

Para a coleta dos dados de tempos e movimentos (VALVERDE et al., 1996; SEIXAS et al., 2004; FERNANDES et al., 2009) foi empregado o método de tempo continuo que consiste em realizar as medições sem a parada do cronometro (FIEDLER et al., 2008; OLIVEIRA JR. Et al., 2009; SIMÕES et al., 2010b; SIMÕES et al., 2010a; SIMÕES et al., 2014).

Cada feixe de madeira formado durante a derrubada foi considerado um ciclo operacional.

O ciclo operacional, por sua vez, era composto por atividades parciais efetivas e gerais.

As atividades efetivas eram aquelas compostas por movimentos planejados que ocorriam durante a rotina de trabalho e resultavam em produção.

Já as atividades gerais, que ocorriam eventualmente, não resultavam em produção.

\section{Descrição das atividades efetivas}

As atividades efetivas do ciclo operacional do feller buncher foram:

- Cortar: compreende o tempo despendido para o corte, acúmulo das árvores e formação do feixe de madeira. Esta atividade inicia no momento em que o cabeçote direciona-se até a primeira árvore e finaliza no momento do último corte da árvore de cada feixe. 
Miyajima et al. - A Influência da declividade do terreno e do tempo

de experiência dos operadores no rendimento do feller buncher

- Bascular: tempo despendido para a deposição do feixe de madeira no solo. Inicia após o corte da última árvore de cada feixe e termina com a abertura das garras do cabeçote e deposição das árvores sobre o solo.

- Girar vazio: tempo despendido para a máquina retornar a posição de corte. Inicia-se com o movimento do cabeçote após a basculada e termina com o posicionamento do mesmo até a primeira árvore.

- Arrumar feixe: tempo despendido para a arrumação dos feixes de madeira. Inicia-se quando a máquina alinha uma árvore ou mais em um feixe de madeira e termina com a árvore posta no feixe de madeira.

- Pegar árvore: tempo despendido para a coleta de uma árvore caída do ciclo anterior. Inicia-se a partir do momento que o cabeçote é direcionado para a árvore caída e termina com a mesma posta no feixe de madeira.

\section{Descrição das atividades gerais}

A única atividade geral do ciclo operacional que ocorreu durante o estudo foi:

- Interrupções: consiste no tempo de parada da máquina para manutenções mecânicas e tempo pessoal do operador.

\section{Cálculo do número amostral}

O número mínimo de ciclos operacionais foi calculado através de um estudo piloto com um erro amostral admissível fixado em 5\%, a 95\% de probabilidade (Equação 1), conforme descrito por diversos autores (FIEDLER et al., 2008; OLIVEIRA JR. et al., 2009; SIMÕES et al, 2010a; SIMÕES et al., 2010b; SIMÕES et al., 2014).

$$
\mathrm{n}=\frac{\mathrm{t}^{2} \cdot C V^{2}}{\mathrm{E}^{2}}
$$

Em que:

n - número mínimo de ciclos operacionais necessários

$\mathrm{t}$ - valor de t, Student, no nível de probabilidade desejado e (n-1) graus de liberdade

CV - coeficiente de variação (\%)

E - erro admissível (\%)

Durante o estudo piloto foram coletados 30 ciclos para cada operador em ambas as declividades. A partir destes dados foi calculado o número mínimo de ciclos necessários (Tabela 2).

O número de ciclos coletados no estudo de campo foi superior ao calculado no estudo piloto (Tabela 2).

Tabela 2. Suficiência amostral e número de ciclos coletados.

Table 2. Adequate sampling and number of collected cycles.

\begin{tabular}{llccc}
\hline \multirow{2}{*}{ Declividades } & \multirow{2}{*}{ Número de ciclos } & \multicolumn{3}{c}{ Operadores } \\
\cline { 3 - 5 } Ondulada & Calculado & $\mathbf{1}$ & $\mathbf{2}$ & $\mathbf{3}$ \\
& Coletado & - & 125 & 58 \\
\multirow{2}{*}{ Plana } & Calculado & 36 & 300 & 300 \\
\hline & Coletado & 300 & 300 & 100 \\
\end{tabular}

\section{Rendimento}

O rendimento foi calculado em metros cúbicos de madeira cortada por hora efetiva de trabalho $\left(\mathrm{m}^{3} \mathrm{~h}^{-1}\right)$ (Equação 2).

Em que:

$$
\mathrm{R}=\frac{\mathrm{V}}{\mathrm{He}}
$$

$\mathrm{R}$ - rendimento $\left(\mathrm{m}^{3} \mathrm{~h}^{-1}\right)$

$\mathrm{V}$ - volume de madeira $\left(\mathrm{m}^{3}\right)$

He - tempo efetivo de trabalho (horas) 
O volume de madeira cortada foi obtido por meio da multiplicação do numero de árvores colhidas pelo volume médio das árvores.

O volume médio das árvores, por sua vez, foi obtido por meio de um inventário da área experimental.

\section{Eficiência operacional}

O cálculo da eficiência operacional foi realizado utilizando a (Equação 3).

De acordo com Oliveira et al. (2009), a eficiência operacional é a percentagem do tempo efetivamente trabalhado, em relação ao tempo destinado ao trabalho.

Em que:

$$
\mathrm{Eo}=\frac{\mathrm{He}}{\mathrm{He}+\mathrm{Hp}} \cdot 100
$$

Eo - eficiência operacional (\%)

He - tempo efetivo de trabalho (horas)

Hp - tempo de interrupções (horas)

\section{Rendimento médio}

O rendimento médio, calculado para cada operador e para cada declividade, foi obtido através da divisão do somatório dos rendimentos dos ciclos operacionais pelo número de ciclos (Equação 4).

Em que:

$$
\mathrm{Rm}=\frac{\mathrm{RR}}{\mathrm{n}}
$$

$\mathrm{Rm}$ - rendimento médio $\left(\mathrm{m}^{3} \mathrm{~h}^{-1}\right)$

$\Sigma \mathrm{R}$ - somatório dos rendimentos $\left(\mathrm{m}^{3} \mathrm{~h}^{-1}\right)$

$\mathrm{n}$ - ciclos operacionais (nr)

\section{Tempo efetivo médio}

O tempo efetivo médio foi obtido através da divisão do somatório dos tempos efetivos dos ciclos operacionais pelo número de ciclos (Equação 5).

Em que:

$$
\mathrm{Tem}=\frac{\Sigma \mathrm{He}}{\mathrm{n}}
$$

Tem - tempo efetivo médio (minutos)

$\Sigma$ He - somatório do tempo efetivo de trabalho (minutos)

$\mathrm{n}$ - ciclos operacionais (nr)

\section{Metodologia Estatística}

$\mathrm{Na}$ análise estatística das variáveis rendimento médio $\left(\mathrm{m}^{3} \mathrm{~h}^{-1}\right)$ e tempo efetivo médio (minutos/ ciclo), foram utilizados modelos lineares generalizados com distribuição de probabilidade gama $e$ função de ligação logarítmica (NELDER; WEDDERBURN, 1972; DIGGLE et al., 2002). Foram considerados os fatores declividade do terreno e tempo de experiência dos operadores.

A qualidade do ajuste dos modelos foi feita através da análise de desvios (deviance). A análise foi feita considerando-se a estrutura fatorial, isto é, o estudo de um dado fator foi feito dentro dos níveis do outro fator.

Para comparações entre tratamentos foi utilizado o teste LS Means do procedimento Genmod do programa SAS - Statistical Analysis System (SAS, 2012).

\section{RESULTADOS E DISCUSSÃO}

A seguir são apresentados os resultados do rendimento médio, eficiência operacional, tempo efetivo médio por ciclo e das atividades parciais do feller buncher.

Ao avaliar o harvester na colheita de eucalipto Simões e Fenner (2010) concluíram que a declividade do terreno foi um dos fatores que mais influenciam o rendimento operacional desta máquina na colheita de florestas de eucalipto e que a produtividade decresceu com o aumento do percentual de inclinação do relevo. 
O mesmo efeito foi observado no presente estudo. Na Figura 1 são apresentados os rendimentos médios $\left(\mathrm{m}^{3} \mathrm{~h}^{-1}\right)$ e desvios padrão dos operadores do feller buncher nas declividades plana e ondulada. Independentemente do tempo de experiência do operador o rendimento decresceu a medida que a declividade aumentou.

Por outro lado, Leonello et al. (2012), ao estudar o tempo de experiência dos operadores de harvester concluíram que o rendimento aumentou expressivamente nos primeiros 18 meses de experiência, mantendo-se em ascensão até os 44 meses de experiência.

Resultados semelhantes foram constatados no presente estudo, ou seja, verifica-se na Figura 1 que o rendimento foi maior quanto maior o tempo de experiência dos operadores.

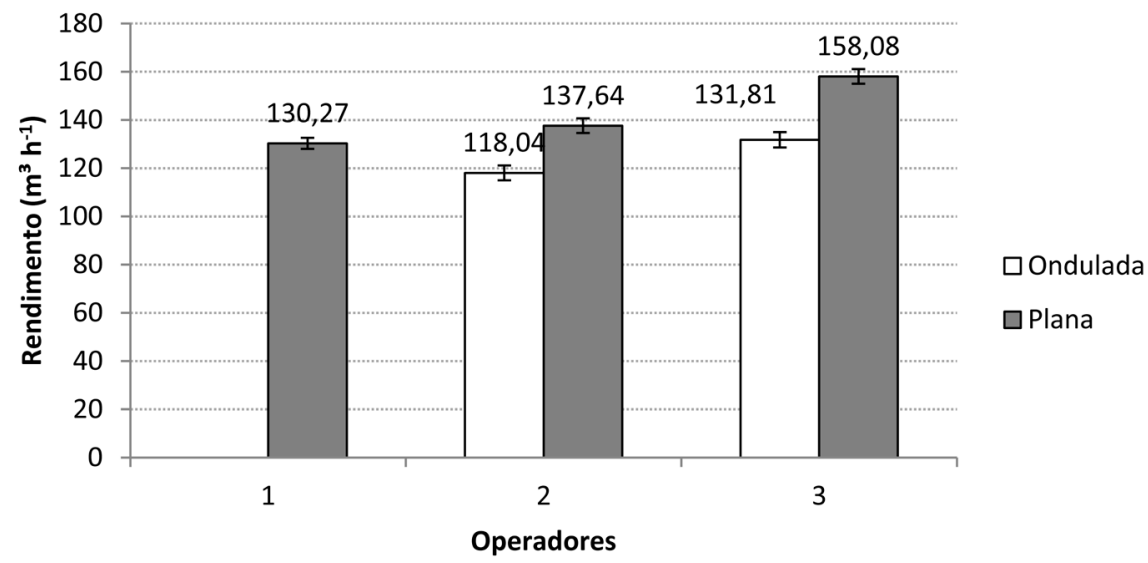

Figura 1. Rendimento médio dos operadores $\left(\mathrm{m}^{3} \mathrm{~h}^{-1}\right)$ segundo declividades. As barras verticais representam os intervalos de confiança para as médias ao nível de $95 \%$.

Figure 1. Mean yield $\left(\mathrm{m}^{3} \mathrm{~h}^{-1}\right)$ of operators according slopes. Vertical bars are confidence interval of the means about $95 \%$.

Conforme apresentado na Tabela 3, houve diferença significativa no rendimento entre os operadores, sendo que o maior rendimento foi obtido pelo operador com maior tempo de experiência. Também é possível verificar que há diferença no rendimento entre as duas declividades. O melhor rendimento foi obtido para a declividade plana.

Tabela 3. Rendimento médio $\left(\mathrm{m}^{3} \mathrm{~h}^{-1}\right)$ e desvio padrão dos operadores e declividades.

Table 3. Mean yield $\left(\mathrm{m}^{3} \mathrm{~h}^{-1}\right)$ and standard deviation of operators and slopes.

\begin{tabular}{|c|c|c|c|c|}
\hline \multirow{2}{*}{ Declividades } & \multicolumn{3}{|c|}{ Operadores } & \multirow{2}{*}{ Média } \\
\hline & 1 & 2 & 3 & \\
\hline Ondulada & & $\begin{array}{l}118,04 \text { Aa } \\
(27,11)\end{array}$ & $\begin{aligned} & 131,81 \mathrm{Ba} \\
&(28,07) \\
&\end{aligned}$ & 124,92 \\
\hline Plana & $\begin{array}{l}130,27 \quad C \\
(20,25)\end{array}$ & $\begin{array}{l}137,64 \mathrm{Ab} \\
(26,50)\end{array}$ & $\begin{aligned} & 158,08 \mathrm{Bb} \\
&(26,94)\end{aligned}$ & 142,00 \\
\hline
\end{tabular}

Médias seguidas da mesma letra maiúscula na linha ou mesma letra minúscula na coluna não tem diferença estatística pelo LS Means $(\mathrm{p}<0,05)$.

Os operadores apresentaram rendimentos médios estatisticamente diferentes. Para a declividade ondulada o rendimento médio variou de $118,04 \mathrm{~m}^{3} \mathrm{~h}^{-1}$ a $131,81 \mathrm{~m}^{3} \mathrm{~h}^{-1}$. Para a declividade plana $\mathrm{o}$ rendimento médio variou de $130,27 \mathrm{~m}^{3} \mathrm{~h}^{-1}$ a $158,08 \mathrm{~m}^{3} \mathrm{~h}^{-1}$.

O operador com maior tempo de experiência também apresentou maior rendimento, independentemente da declividade.

A influência da declividade em relação ao rendimento médio também apresentou diferenças significativas. O operador 2 apresentou um rendimento médio variando de 118,04 $\mathrm{m}^{3} \mathrm{~h}^{-1}$ a 137,64 $\mathrm{m}^{3} \mathrm{~h}^{-1}$, já para o operador 3 o rendimento variou de 131,81 $\mathrm{m}^{3} \mathrm{~h}^{-1}$ a 158,08 $\mathrm{m}^{3} \mathrm{~h}^{-1}$. Em média o rendimento na declividade ondulada foi de $124,92 \mathrm{~m}^{3} \mathrm{~h}^{-1}$, e na declividade plana foi de $142,00 \mathrm{~m}^{3} \mathrm{~h}^{-1}$.

Verifica-se na Figura 2 que independentemente do tempo de experiência dos operadores os maiores rendimentos foram constatados para a declividade plana. Por outro lado verifica-se que, independentemente da declividade do terreno, o rendimento aumenta com o aumento do tempo de experiência dos operadores. 


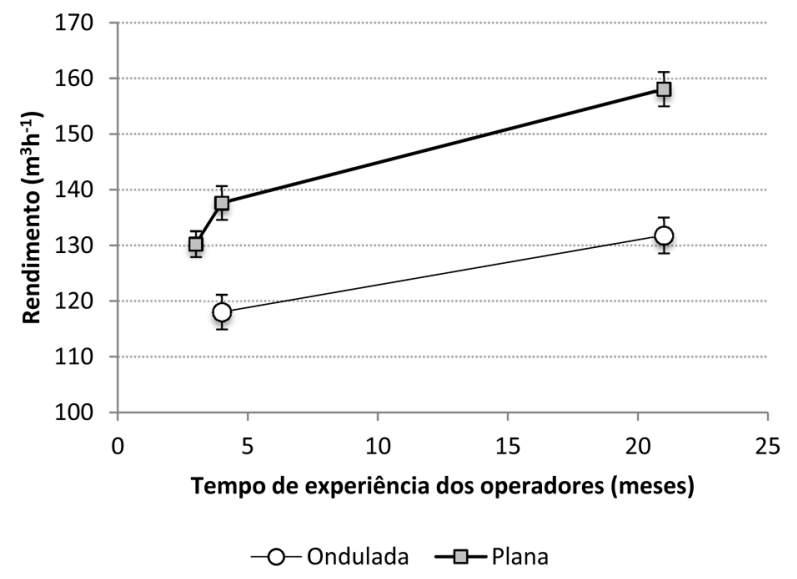

Figura 2. Rendimento médio dos operadores $\left(\mathrm{m}^{3} \mathrm{~h}^{-1}\right)$ em função do tempo de experiência, segundo declividades. As barras verticais representam os intervalos de confiança para as médias ao nível de $95 \%$.

Figure 2. Mean yield $\left(\mathrm{m}^{3} \mathrm{~h}^{-1}\right)$ of operators related to the time of experience, according to the slopes. Vertical bars are confidence interval of the means about $95 \%$.

O ganho de rendimento, quando comparada a declividade plana em relação a declividade ondulada, foi de 16,60\% para o operador 2 e de 19,93\% para o operador 3.

Oliveira Jr. et al. (2009) analisando a produtividade do feller buncher em um povoamento de eucalipto, também verificaram maior rendimento para a declividade plana em relação à ondulada. O mesmo comportamento foi constatado por Leite et al. (2014) ao estudar um harvester.

A eficiência operacional foi estudada por diversos autores Fiedler et al. (2008); Rocha et al. (2009) concluíram que as intervenções mecânicas estão entre os principais fatores que afetam a eficiência operacional. O mesmo comportamento foi observado no presente estudo. A baixa eficiência operacional no terreno ondulado pode ser explicada por uma interrupção, devido a intervenção mecânica ocasionada por uma quebra da máquina.

A eficiência operacional dos operadores 1, 2 e 3, na declividade plana, corresponderam a $67,20 \%$, $65,85 \%$ e $77,77 \%$ respectivamente.

Já para a declividade ondulada, a eficiência operacional foi de $44,51 \%$ para o operador 2 e de $38,44 \%$ para o operador 3 .

De acordo com a Tabela 4, comparando o tempo efetivo médio por declividade, verifica-se que os operadores são diferentes. Já, quando comparamos o mesmo operador nas diferentes declividades, somente o operador 3 apresentou diferença estatística, sendo o menor tempo para a declividade plana.

Tabela 4. Tempo efetivo médio por ciclo (minutos) e desvio padrão dos operadores e declividades.

Table 4. Mean effective time per cycle (minutes) and standard deviation of operators and slopes.

\begin{tabular}{|c|c|c|c|c|}
\hline \multirow{2}{*}{ Declividades } & \multicolumn{3}{|c|}{ Operadores } & \multirow{2}{*}{ Média } \\
\hline & 1 & 2 & 3 & \\
\hline \multirow[t]{2}{*}{ Ondulada } & & $0,80 \mathrm{Aa}$ & $0,75 \mathrm{Ba}$ & 0,77 \\
\hline & & $(0,16)$ & $(0,17)$ & \\
\hline Plana & $\begin{array}{r}0,82 \mathrm{C} \\
(0,21)\end{array}$ & $\begin{array}{r}0,78 \text { Aa } \\
(0,16)\end{array}$ & $\begin{array}{r}0,69 \mathrm{Bb} \\
(0,15)\end{array}$ & 0,76 \\
\hline
\end{tabular}

Médias seguidas da mesma letra maiúscula na linha ou mesma letra minúscula na coluna não tem diferença estatística pelo LS Means $(p<0,05)$.

O menor tempo efetivo médio por ciclo obtido pelo operador 3 na declividade plana (Tabela 4) resultou em um maior rendimento (Tabela 3 ).

Na declividade plana o tempo efetivo médio foi de 0,76 minutos por ciclo e na declividade ondulada foi de 0,77 minutos por ciclo.

A declividade do terreno e o tempo de experiência dos operadores influenciaram no rendimento médio e no tempo efetivo médio dos operadores.

Independentemente da declividade do terreno e do tempo de experiência do operador a atividade parcial do feller buncher que mais consumiu tempo foi o corte. Este resultado corrobora com os obtidos por Minette et al. (2008), Fernandes et al. (2009), Nascimento et al. (2011) e Simões et al. (2014). A segunda atividade parcial que mais consumiu tempo foi o giro vazio e a terceira foi a basculada. 
Miyajima et al. - A Influência da declividade do terreno e do tempo

de experiência dos operadores no rendimento do feller buncher

\section{CONCLUSÕES}

Independentemente do tempo de experiência o rendimento foi maior no terreno plano em relação ao ondulado.

Independentemente da declividade do terreno o rendimento aumentou com o aumento do tempo de experiência dos operadores.

A eficiência operacional foi maior na declividade plana em relação a ondulada.

A atividade parcial cortar foi a que mais consumiu tempo, seguido do giro vazio e da basculada.

\section{AGRADECIMENTOS}

Os autores agradecem a Coordenação de Aperfeiçoamento de Pessoal de Nível Superior (CAPES), pelo suporte financeiro para a realização do presente estudo.

\section{REFERÊNCIAS BIBLIOGRÁFICAS}

BERTIN, V. A. S. Análise de dois modais de sistemas de colheita mecanizados de eucalipto em primeira rotação. 2010. 74 p. Dissertação (Mestrado em Agronomia Energia na Agricultura) Universidade Estadual Paulista Júlio de Mesquita Filho, Botucatu, 2010.

BRAMUCCI, M.; SEIXAS, F. Determinação e quantificação de fatores de influencia sobre a produtividade de "harvesters" na colheita florestal. Scientia Forestalis, Piracicaba, n. 62, p. 62-74, 2002.

DIGGLE, P. J.; HEAGERTY, P.; LIANG, K. Y.; ZEGER, S. L. Analysis of Longitudinal Data. 2.ed. Oxford: Oxford Science Publications, 2002. 379 p.

FERNANDES, H. C.; LOPES, S. E.; TEIXEIRA, M. M.; MINETTE, L. J, RINALDI, P. C. N.; BERNARDES, A. M. Avaliação das características técnica e econômica de um sistema de colheita florestal de árvores inteiras. Scientia Forestalis, Piracicaba, v. 37, n. 83, p. 225-232, set. 2009.

FIEDLER, N. C.; ROCHA, E. B.; LOPES, E. S. Análise da produtividade de um sistema de colheita de árvores inteiras no norte do Estado de Goiás. Floresta, Curitiba, v. 38, n. 4, p. 577-586, 2008.

LEITE, E. S.; MINETTE, L. J.; FERNANDES, H. C.; SOUZA, A. P.; AMARAL, E. J.; LACERDA, E. G. Desempenho do harvester na colheita de eucalipto em diferentes espaçamentos e declividades. Revista Árvore, Viçosa, v. 38, n. 1, p. 95-101, 2014.

LEONELLO, E. C.; GONÇALVES, S. P.; FENNER, P. T. Efeito do tempo de experiência de operadores de harvester no rendimento operacional. Revista Árvore, Viçosa, v. 36, n. 6, p. 1129-1133, 2012.

LOPES, E. S. CRUZINIANI, E.; ARAUJO, A. J.; SILVA, P. C. Avaliação do treinamento de operadores de harvester com uso de simulador de realidade virtual. Revista Árvore, Viçosa, v. 32, n. 2, p. 291-298, 2008.

LOPES, S. E.; FERNANDES, H. C.; SANTOS, N. T.; RINALDI. P. C. N. Avaliação técnica e econômica de uma garra traçadora operando em diferentes produtividades. Scientia Forestalis, Piracicaba, v. 36, n. 79, p. $215-$ 222, 2008. (Verificar A e B)

MALINOVSKI, J. R.; MALINOVSKI, R. A. Evolução dos sistemas de colheita de Pinus na região sul do Brasil. Curitiba: FUPEF, 1998. 138 p.

MALINOVSKI, R. A.; MALINOVSKI, R. A.; MALINOVSKI, J. R.; YAMAJI, Y. F. M. Análise nas variáveis de influência na produtividade das máquinas de colheita de madeira em função das características físicas do terreno, do povoamento e do planejamento operacional florestal. Floresta, Curitiba, v. 36, n. 2, p. 169-182, 2006.

MINETTE, L. J. MOREIRA, F. M. T.; SOUZA, A. P.; MACHADO, C. C.; SILVA, K. R. Análise técnica e econômica do forwarder em três subsistemas de colheita em florestas de eucalipto. Revista Árvore, Viçosa, v. 28, n. 1, p. 91-297, 2004. 
MINETTE, L. J.; SILVA, E. N.; FREITAS, K. E.; SOUZA, A. P.; SILVA, E. P. Análise técnica e econômica da colheita florestal mecanizada em Niquelândia, Goiás. Revista Brasileira de Engenharia Agrícola e Ambiental, Campina Grande, v. 12, n. 6, p. 659-665, nov./dez. 2008.

MOREIRA, F. M. T.; SOUZA, A. P.; MACHADO, C. C.; MINETTI, L. J.; SILVA, K. R. Avaliação operacional e econômica do feller buncher em dois subsistemas de colheita de florestas de eucalipto. Revista Árvore, Viçosa, v. 28, n. 2, p. 199-205, 2004.

NASCIMENTO, A. C.; LEITE, A. M. P.; SOARES, T. S.; FREITAS, L. C. Avaliação técnica e econômica da colheita florestal com feller buncher. Cerne, Lavras, v. 17, n. 1, p. 9-15, jan./mar. 2011.

NELDER, J. A.; WEDDERBURN, R. W. Generalized linear models. Journal of the Royal Statistical Society Series A, v. 135, n. 3, p. 370-384, 1972.

OLIVEIRA, D.; LOPES, E. S.; FIEDLER, N. C. Avaliação técnica e econômica do forwarder em extração de toras de pinus. Scientia Forestalis, Piracicaba, v. 37, n. 84, p. 525-533, 2009.

OLIVEIRA JR., E. D.; SEIXAS, F.; BATISTA, J. L. F. Produtividade de feller buncher em povoamento de eucalipto em relevo acidentado. Floresta. Curitiba, v. 39, n. 4, p. 905-912, 2009.

ROCHA, E. B.; FIEDLER, N. C.; ALVES, R. T.; LOPES, E. S.; GUIMARÃES, P. P.; PERONI, L. Produtividade e custos de um sistema de colheita de árvores inteiras. Cerne, Lavras, v. 15, n. 3, p. 372-381, 2009.

SAS. Statistical analysis system for Windows. Release 9.2.Cary, 2012.

SEIXAS, F; BARBOSA, R. F.; RUMMER, R. Tecnologia que protege a saúde do operador. Revista da Madeira, Curitiba, v. 14, n. 82, p. 68-73, 2004.

SILVA, C. B.; SANT'ANNA, C. M.; MINETTE, L. J. Avaliação ergonômica do feller buncher utilizado na colheita de eucalipto. Cerne, Lavras, v. 9, n. 1, p. 109-118, 2003.

SIMÕES, D. Avaliação econômica de dois sistemas de colheita florestal mecanizada de eucalipto. 2008. 104 p. Dissertação (Mestrado em Agronomia Energia na Agricultura) Universidade Estadual Paulista Júlio de Mesquita Filho, Botucatu, 2008.

SIMÕES, D.; FENNER, P. T. Influência do relevo na produtividade e custos do harvester. Scientia Forestalis, Piracicaba, v. 38, n. 85, p. 107-114, 2010.

SIMÕES, D.; FENNER, P. T.; ESPERANCINI, M. S. T. Avaliação técnica e econômica da colheita de florestas de eucalipto com harvester. Scientia Forestalis, Piracicaba, v. 38, n. 88, p. 611-618, 2010a.

SIMÕES, D. FENNER, P. T.; ESPERANCINI, M. S. T. Produtividade e custos do feller buncher e Processador Florestal em povoamentos de eucalipto de primeiro corte. Ciência Florestal, Santa Maria, v. 24, n. 3, p. 621630, jul./set. 2014.

SIMÕES, D.; IAMONTI, I. C., FENNER, P. T. Avaliação técnica e econômica do corte de eucalipto com feller buncher em diferentes condições operacionais. Ciência Florestal. Santa Maria, v. 20, n. 4, p. 649-656, 2010 b.

VALVERDE, S. R.; MACHADO, C. C.; REZENDE, J. L. P.; SOUZA, A. P.; ANTIQUEIRA, A. C. Análise técnicoeconômica do corte de madeira com o trator florestal derrubador-amontoador (feller buncher) no sistema de colheita florestal de árvores inteiras de eucalipto. Revista Árvore, Viçosa, v. 20, n. 2, p. 229-40, 1996.

Recebido em 22/07/2015

Aceito para publicação em 10/12/2015

Sci. For., Piracicaba, v. 44, n. 110, p. 443-451, jun. 2016

DOI: dx.doi.org/10.18671/scifor.v44n110.17 
